\title{
Growth and metabolism of Beauveria bassiana spores and mycelia
}

\author{
Hongxia Liu', Xusheng Zhao', Mingxin Guo', Hui Liu² and Zhiming Zheng²*
}

\begin{abstract}
Background: Fungi are ubiquitous in nature and have evolved over time to colonize a wide range of ecosystems including pest control. To date, most research has focused on the hypocrealean genera Beauveria bassiana, which is a typical filamentous fungus with a high potential for insect control. The morphology and components of fungi are important during the spores germination and outgrow to mycelia. However, to the best of our knowledge, there is no report on the morphology and components of B. bassiana spores and mycelia. In the work, the growth and metabolism of Beauveria bassiana spores and mycelia were studied. High performance liquid chromatography-mass spectrometry (HPLC-MS) was employed to study the metabolism of B. bassiana spores and mycelia. Principal component analysis (PCA) based on HPLC-MS was conducted to study the different components of the spores and mycelia of the fungus. Metabolic network was established based on HPLC-MS and KEGG database.

Results: Through Gompertz model based on macroscopic and microscopic techniques, spore elongation length was found to increase exponentially until approximately $23.1 \mathrm{~h}$ after cultivation, and then growth became linear. In the metabolic network, the decrease of glyoxylate, pyruvate, fumarate, alanine, succinate, oxaloacetate, dihydrothymine, ribulose, acetylcarnitine, fructose-1, 6-bisphosphate, mycosporin glutamicol, and the increase of betaine, carnitine, ergothioneine, sphingosine, dimethyl guanosine, glycerophospholipids, and in spores indicated that the change of the metabolin can keep spores in inactive conditions, protect spores against harmful effects and survive longer.

Conclusions: Analysis of the metabolic pathway in which these components participate can reveal the metabolic difference between spores and mycelia, which provide the tools for understand and control the process of of spores germination and outgrow to mycelia.
\end{abstract}

Keywords: Beauveria bassiana, Gompertz model, PCA, HPLC-MC, Metabolism

\section{Background}

Fungi are ubiquitous in nature and have evolved over time to colonize a wide range of ecosystems including pest control. Over the past century, approximately 1000 fungal species have been reported to kill insects [1-3]. To date, most research has focused on the hypocrealean genera Beauveria bassiana, which is a typical filamentous fungus with a high potential for insect control, because its spores are relatively easy and inexpensive to mass produce for field applications [4-6]. Moreover, it is known to have nontoxic effects on nontarget organisms,

\footnotetext{
* Correspondence: zhimingz2015@163.com

${ }^{2}$ Key Laboratory of Ion Beam Bioengineering, Hefei Institutes of Physical Science, Chinese Academy of Sciences and Anhui Province, Hefei, Anhu 230031, P. R. China

Full list of author information is available at the end of the article
}

including animals and humans [7]. killing insect by fungi is a process of spore germination and outgrow to mycelia [8], which can be concluded as follows: as soon as a fungal spore is exposed to its favourable conditions, it changes from a dormant state to an actively metabolizing cell, and then a germ tube emerges from the spore. When the germ tube reaches a certain length, the spore is considered to be germinated. In the next steps, germ tube elongation and branching take place until the mycelium forms a colony [9]. The process has been assessed through typical reverse genetic gene-specific studies in terms of cell division [10], trehalose metabolism [11], respiration $[12,13]$, and nucleic and protein synthesis during spore germination [14]. We can conclude that the morphology and components of fungi during spores outgrowth to mycelia are changed $[15,16]$. However, to the best of our 
knowledge, there is no report on the morphology and components of B. bassiana spores and mycelia. The change of morphology and components can reveal the connection between spores and mycelia, and provide a systems-level understanding of the cell.

Despite its importance, only a limited number of methodologies have been developed for morphology and components analysis. This is primarily due to the characteristics of most components that display high polarity, nonvolatility, poor detectability, and overall similar properties [17]. Recently, high performance liquid chromatography - mass spectrometry (HPLC-MS) equipped with electrospray ionization (ESI) detection has been used for components analysis [18-21]. It is a robust, sensitive, and selective technique, and also has become popular for quantitative and qualitative analyses. In the present study, the morphology of $B$. bassiana spores and mycelia were studied by combining macroscopic and microscopic techniques. And then HPLC-MS coupled with PCA were used to distinguish different metabolites of mycelia and spores. In addition, metabolic pathway was established based on HPLC-MS and KEGG database. Tracking metabolite changes under different conditions not only provides direct information on metabolism but is also complementary to gene expression and proteome analysis [22, 23]. Metabolomics, which can be defined as the measurement of the level of all intracellular metabolites, has become a powerful new tool for gaining insight into cellular function. The aim of the study was to reveal the reason of keep survive longer and infective of spores by compare significant change in metabolites between spores and mycelia. And provide the tools for understand and control the process of spores germination and outgrow to mycelia.

\section{Results and discussion}

Spore germination kinetics

The germination of spores takes place when the spores are introduced into a proper environment, which requires proper nutrition and special conditions. The spore germination can be divided into three phases: spore swelling, germ tube emergence and germ tube elongation [9]. In the first phase, spores begin to swell to increase their dormant diameter significantly until a germ tube emerges (second phase). The two phases in early growth are supported by mobilization and utilization of storage compounds in the spores. In the third phase the elongation of the germ tube is observed, which contributes to biosynthesis and extension by uptake and metabolism of nutrients from the medium [15].

The spore germination kinetics was investigated in the study. The values for hyphal length were measured with the aid of Image-Pro Plus software in a series of images monitoring the growth of B. bassiana spores on PDA at
$26{ }^{\circ} \mathrm{C}$, and the duration of the germination phase was estimated. Until the 6th hour of the cultivation, no germ tubes could be spotted, although an increase in the mean diameter of spores due to swelling. (Fig. 1).

Figure 1 showed typical forms of B. bassiana spores and hyphae in their development. Tubes emerged from $8 \mathrm{~h}$ to approximately $11 \mathrm{~h}$. About $10 \mathrm{~h}$ after cultivation, most of the spores had their tubes emerged. At that moment the spores entered the phase of tube elongation. The hyphae remained unbranched till the 20th hour. After $28 \mathrm{~h}$, the objects became difficult to observe and analyse due to their increasing concentration and aggregation of hyphal elements.

Models were used to describe the behavior of microorganisms [24]. In the study, the modified Gompertz model was employed to detect the relation between spore elongation length and culture time, which can provide useful information about the variance of the germination time for individual spores. Figure 2 showed changes of the most important morphological parameters. It can be seen that the modified Gompertz equation described satisfactorily the length of spore elongation over time for B. bassiana, with coefficients of determination $\left(R^{2}\right)$ of 0.9825 . The three phases, spore swelling, germ tube emergence and germ tube elongation can be observed distinctly. In the phase of germ tube emergence and in the early hyphal development, the measured length appeared to increase exponentially until approximately $23.1 \mathrm{~h}$ after cultivation, when growth became linear. The above results are in agreement with the findings of Trinci $[25,26]$, who examined the kinetics of hyphal extension of several fungi, and considered the observed transition from exponential to linear growth can be attributed to the weakness of the hyphal tips to incorporate the increasing material that is being supplied or the deficiency of transporting material from distal hyphal regions.

\section{Principal component analysis}

PCA based on HPLC-MS data was used to study the metabolomic differences of mycelia and spores extracts from $B$. bassiana. PCA is an unsupervised pattern recognition method, which means that no prior knowledge concerning groups or tendencies within the data sets is necessary. PCA is usually employed to reduce the dimensionality of the data and extract essential information from large, mixed data sets [27]. A score plot is applied for the grouping of samples by reducing the dimensionality of the data. The complex data was reduced to two principal components $\mathrm{PC} 1$ and $\mathrm{PC} 2$, which can represent most of the components. The values of the two variables for the observations are called factor scores, two factors scores can be interpreted geometrically as the projections of the observations onto the 


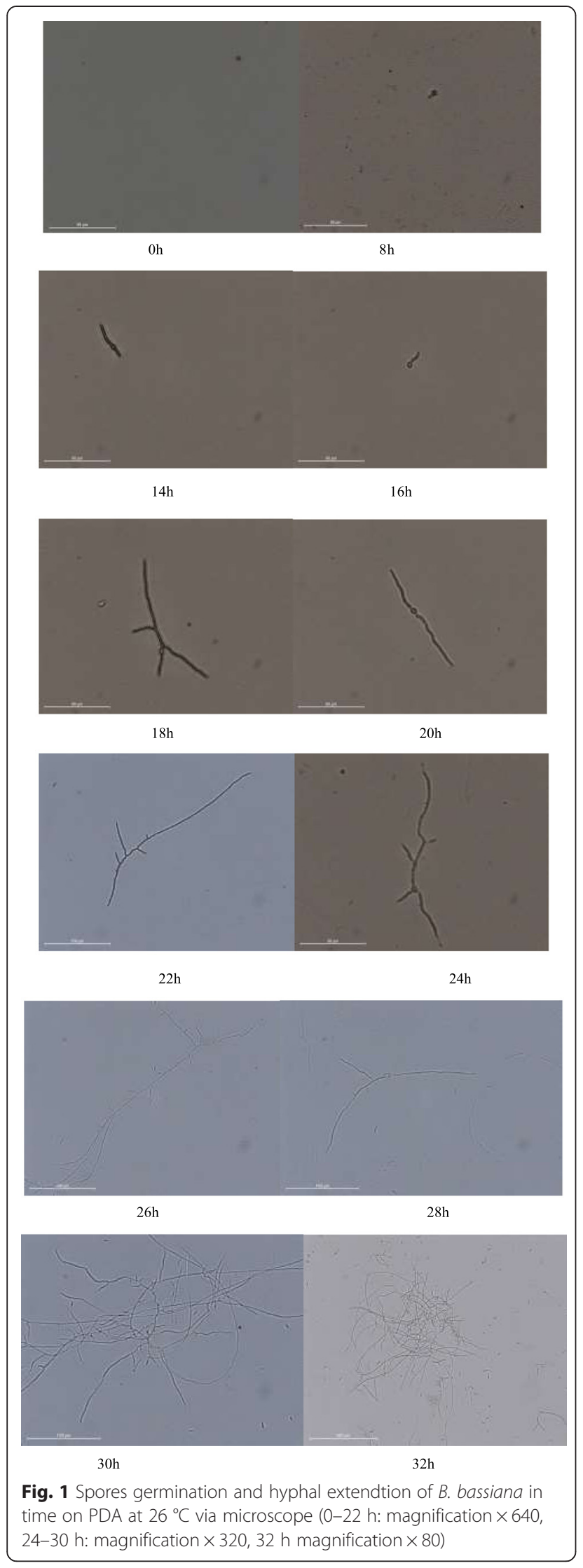

whole components. The data sets exhibiting similarities are clustered together, and those that are different are placed further apart [28].

Acid compounds were extracted in negative mode, while alkaline compounds were extracted in positive mode, to study the whole components extracted from spores and mycelia, both positive mode and negative mode must be employed to PCA. As shown in Fig. 3, from both positive mode and negative mode, PCA score plots employed in this study found that the mycelia were clearly separated from the spores of B. bassiana, and the spores or mycelia were grouped correctly together respectively. In the posotive mode, both principle components were significant: $\mathrm{PC} 1$ accounts for $35.7 \%$ of the total variance and $\mathrm{PC} 2$ accounts for $52.8 \%$. The first two principal components ( $\mathrm{PC} 1$ and $\mathrm{PC} 2$ ) explain more than $80 \%$ of the total variance. In the negative mode, PC2 leads to classification of the two groups and accounts for $58.3 \%$ of the total variance, whereas PC1 denotes $29.5 \%$ of the total variance. The high-resolution ESI-MS data for some metabolites are shown in Fig. 4. These findings were in good agreement with HPLC-MS based metabolic profiles (Tables 1 and 2). In Table 1, twenty-eight major components were identified from $B$. bassiana mycelia by HPLC-MS method, eleven of which were different from that in spores, such as glycerophosphocholine, palmitic acid, linoleic acid, phosphatidylethanolamine. For spores, thirty-six compounds were extracted, seventeen of which were distinguished from mycelia, such as succinic anhydride, dihydrouracil, mannitol, sphinganine (Table 2).

\section{Metabolic pathway analysis}

Nutritional limitations or increase in cell density leads $B$. bassiana to produce dormant, environmentally resistant spores. The complex morphological changes that occur during sporulation are thought to be highly controlled by metabolic networks [29]. However, no comprehensive metabolite profiling approach has been used to demonstrate alterations in large-scale metabolites. Thus, to overall unravel the effects of these metabolites on the metabolic network, HPLC-MS described above was employed to detect the metabolic pathway of some metabolites identified in mycelia and spores.

B. bassiana cells produce spores under conditions of nutrition deprivation. Interestingly, most metabolites (pyruvate, fumarate and ribulose) in the glycolytic, tricarboxylic acid (TCA) cycle and pentose phosphate pathways were markedly decreased in the stage of spores (Fig. 5). In particular, the level of fructose-1, 6bisphosphate, a key factor in catabolite repression, dropped more rapidly in spores than in mycelia. It was possibly because that the decrease in fructose-1, 6bisphosphate resulted in slow of metabolism, which 


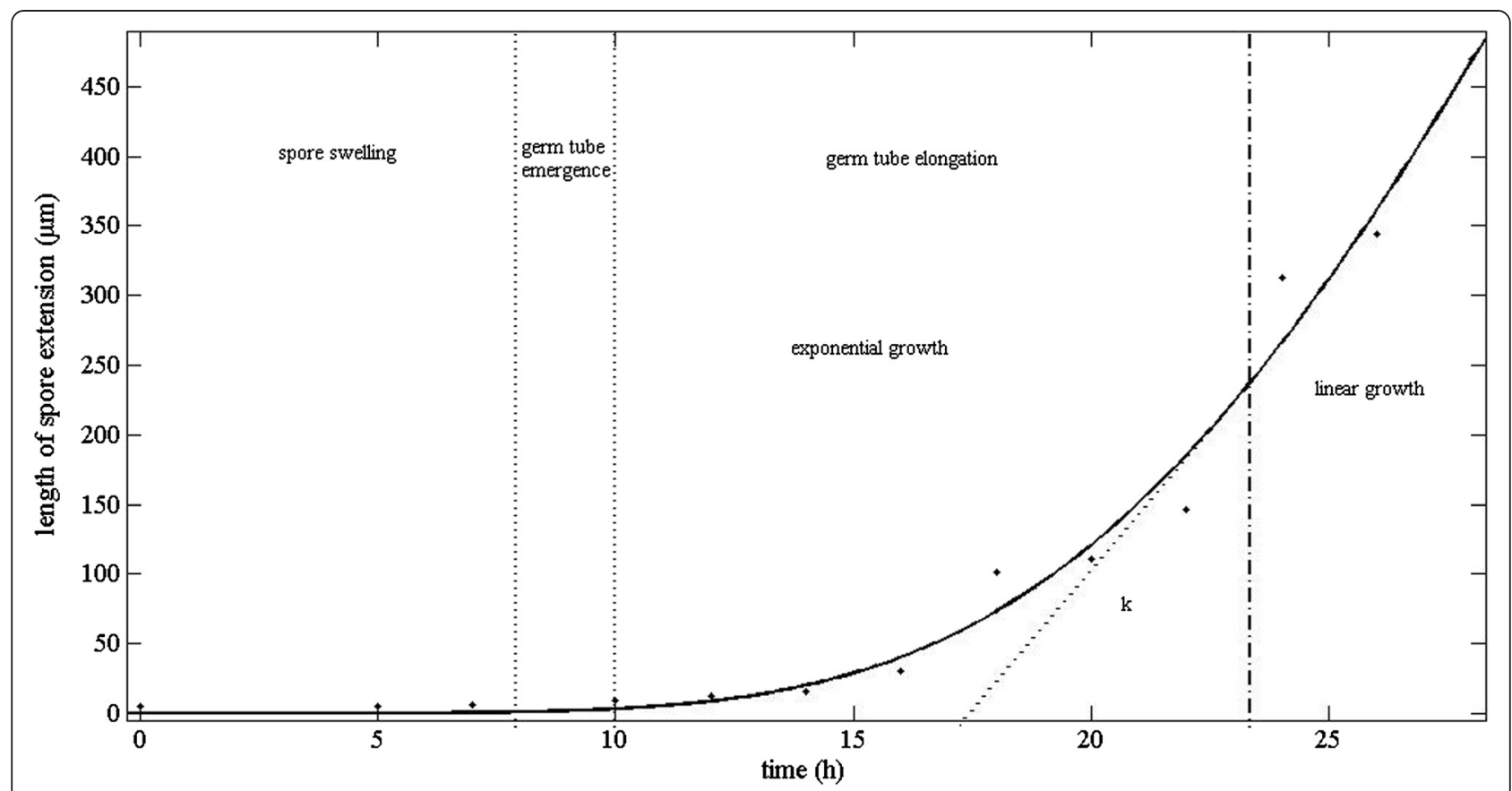

Fig. 2 Germination kinetics of B. bassiana spores on PDA at $26^{\circ} \mathrm{C}$, the lines indicate the fitting of the Gompertz model

kept spores in a dormant, metabolically inactive conditions and help them survive longer.

The pentose phosphate pathway is a biochemical pathway parallel to glycolysis, which can generates $\mathrm{NADPH}$ and pentoses (5-carbon sugars). While it does involve in oxidation of glucose, its primary role is anabolic rather than catabolic [30,31]. The pathway is a major source of reductant for biosynthetic processes such as fatty-acid synthesis and assimilation of inorganic nitrogen [32], and maintains redox potential necessary to protect against oxidative stress [33]. In the first stage of pentose phosphate pathway, glucose-6-phosphate was converted into ribose 5-phosphate, along with the energy production. And then ribose 5-phosphate was converted to phosphoribosyl pyrophosphate (PRPP). At the step, the metabolism was divided into three different pathways: histidine metabolism, purine metabolism and pyrimidine metabolism (Fig. 5). In the histidine metabolism, ergothioneine was extracted from $B$. bassiana as a metabolin, which is a naturally occurring amino acid and a thiourea derivative of histidine only produced by fungi and some prokaryotes. Ergothioneine has antioxidant properties in vitro [34]. Under laboratory conditions, it scavenges hydroxyl radicals and hypochlorous acid, inhibits production of oxidants by metal ions, and may participate in metal ion transport and regulation of metalloenzymes [35, 36]. In 2012, Bello identified an ergothioneine biosynthetic gene Egt-1 in Neurospora crass and demonstrated that ergothioneine enhanced conidial survival and protected against peroxide toxicity during spore germination [37]. Thus, the high levels of ergothioneine in the spores play an antioxidant role, and keep active of spores.

Dimethyl guanosine is a product of purine metabolism. Charles and his co-workers have mentioned that dimethyl guanosine as a self-inhibitor serves to regulate spore development in Dictyostelium mucoroides [38]. Thus, the increased dimethyl guanosine in spores might diminish some gene transcription, which would make metabolism slower [39], and lead to improved shelf life of biological insecticide.

Dihydrothymine is a degradation product of thymine in the pyrimidine metabolism which is catalyzed by dihydropyrimidine dehydrogenase [40]. It associated with valine, leucine and isoleucine metabolism [41]. The decrease of dihydrothymine in spores might mean that the correlative metabolism network became slower than that in mycelia.

A mannitol cycle was first proposed by Hult and Gatenbeck [42], which comprises four enzymes: mannitol 1phosphate dehydrogenase (MPDH), mannitol 1-phosphate phosphatase (MPP), $\mathrm{NADP}^{+}$-mannitol 2-dehydrogenase $(\mathrm{MDH})$, and hexokinase (HX), of which MPDH is the main synthetic enzyme and $\mathrm{MDH}$ is the main catabolic enzyme. The roles of mannitol vary in different fungi and might act as a scavenger of reactive oxygen species [43]. It was found only in spores (not found in mycelia) of $B$. bassiana, which implied that mannitol in spores might have an important impact on environment adaptability, germination, and virulence. 

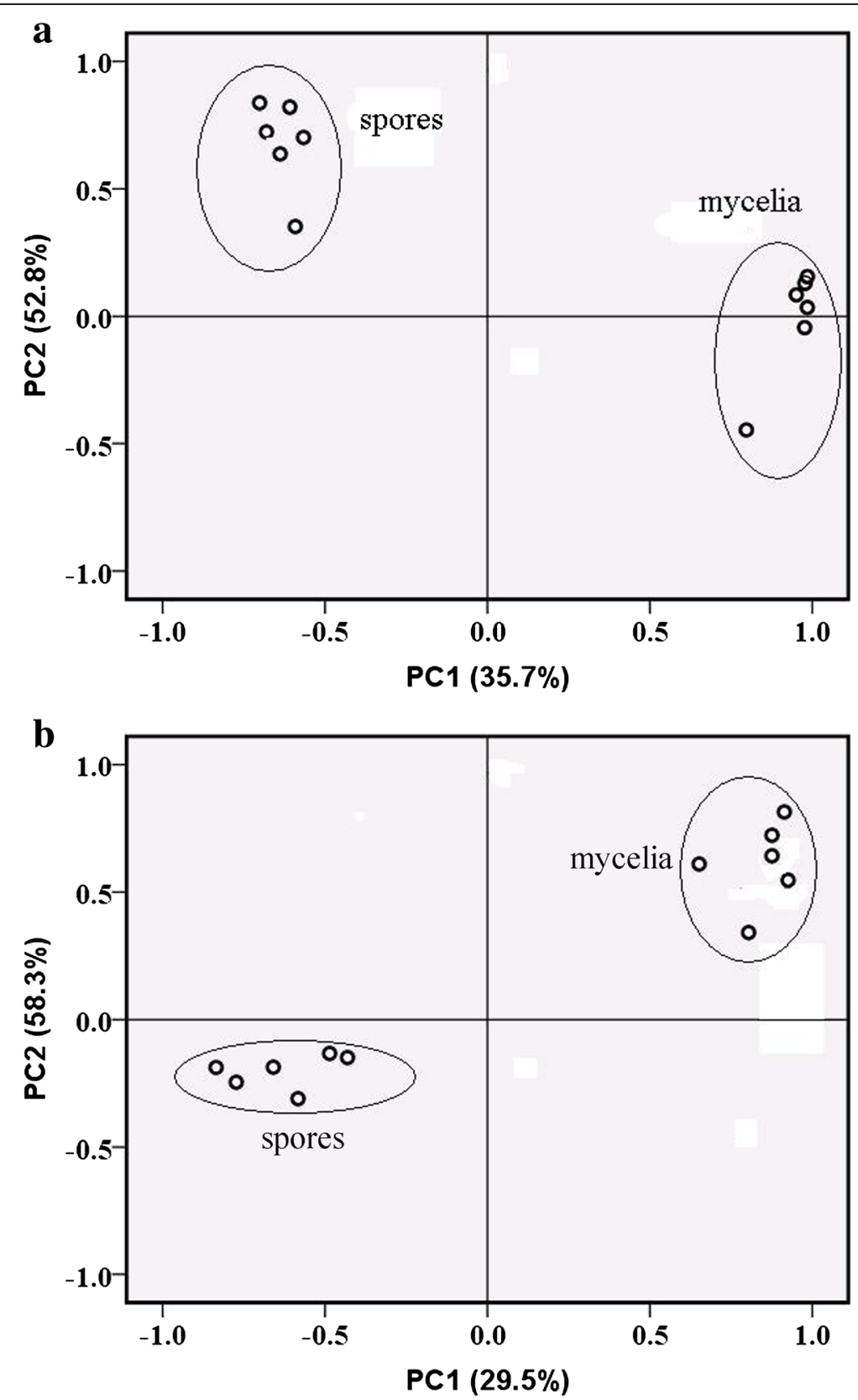

Fig. 3 PCA score plots derived from HPLC - MS spectra of mycelia and spores extracts in positive mode (a) and negative mode (b)

Glycerophospholipids, as glycerol-based phospholipids, are the main components of biological membranes, which play an important role in the generation of both extracellular and intracellular signals. As showed in Fig. 5, the increase of glycerophospholipids, esters and carnitine and the decrease of glyoxylate, pyruvate and acetylcarnitine in spores indicated that the hydrolysis of lipids and oxidation of fatty acids were depressed [44].

Beauverolides are insecticidal cyclodepsipeptides in $B$. bassiana [45]. The emergence of beauverolide $\mathrm{Ka}$ in mycelia (Table 1) may be related to the oxidative stress and/or oxylipin metabolism.

Sphingosine is a signaling lipid and may be involved in insect-fungi recognition, which can recognize the receptors on spores and induce the germination [46]. Sphinganine begins with the condensation of serine with palmitoyl-CoA to form 3-ketosphinganine, which is rapidly reduced to sphinganine [47]. Sphinganine is the biosynthetic precursor of sphingosines and sphingolipids, and its emergence in spores may affect fungal signaling and germination. 


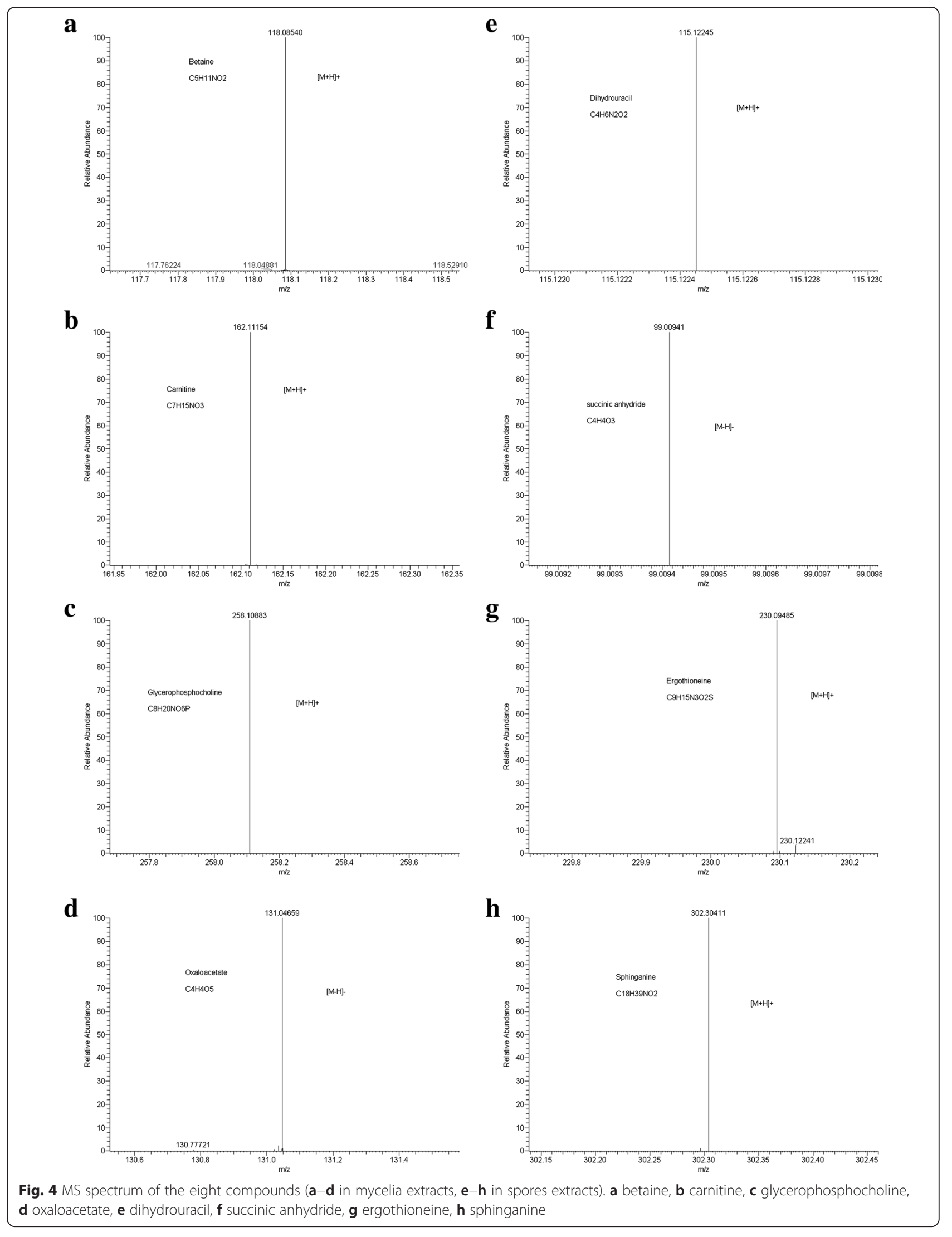


Table 1 Metabolites putatively identified by HPLC - MS in mycelia extracts

\begin{tabular}{|c|c|c|c|c|c|c|c|}
\hline $\mathrm{RT}(\mathrm{min})$ & Detected mass & Metabolite & lonization mode & $\begin{array}{l}\text { Molecular } \\
\text { formula }\end{array}$ & $\begin{array}{l}\text { Theoretical } \\
\text { mass }\end{array}$ & $\Delta$ mass $(\mathrm{mDa})$ & $\begin{array}{l}\text { Relative } \\
\text { concent-ration }\end{array}$ \\
\hline 3.23 & 72.99348 & Glyoxylate & ESI (-) & $\mathrm{C}_{2} \mathrm{H}_{2} \mathrm{O}_{3}$ & 74.00039 & 1.460 & $\uparrow$ \\
\hline 64.92 & 87.00903 & Pyruvate & $\mathrm{ESI}(-)$ & $\mathrm{C}_{3} \mathrm{H}_{4} \mathrm{O}_{3}$ & 88.01739 & -15.625 & $\uparrow$ \\
\hline 1.32 & 90.05431 & Alanine & $\mathrm{ESI}(+)$ and $\mathrm{ESI}(-)$ & $\mathrm{C}_{3} \mathrm{H}_{7} \mathrm{NO}_{2}$ & 89.0932 & -0.645 & $\uparrow$ \\
\hline 5.70 & 115.05154 & Fumarate & ESI (-) & $\mathrm{C}_{4} \mathrm{H}_{4} \mathrm{O}_{4}$ & 116.07216 & 0.758 & $\uparrow$ \\
\hline 2.82 & 117.01965 & Succinate & $\mathrm{ESI}(-)$ & $\mathrm{C}_{4} \mathrm{H}_{6} \mathrm{O}_{4}$ & 118.08804 & 1.415 & $\uparrow$ \\
\hline 1.45 & 118.08540 & Betaine & $\mathrm{ESI}(+)$ & $\mathrm{C}_{5} \mathrm{H}_{11} \mathrm{NO}_{2}$ & 117.07704 & -0.855 & $\downarrow$ \\
\hline 1.17 & 129.13795 & Dihydrothymine & $\mathrm{ESI}(+)$ & $\mathrm{C}_{5} \mathrm{H}_{8} \mathrm{~N}_{2} \mathrm{O}_{2}$ & 128.12922 & 0.952 & + \\
\hline 1.30 & 131.04636 & Oxaloacetate & ESI (-) & $\mathrm{C}_{4} \mathrm{H}_{4} \mathrm{O}_{5}$ & 132.07156 & -1.023 & $\uparrow$ \\
\hline 45.75 & 149.04712 & Ribulose & $\mathrm{ESI}(-)$ & $\mathrm{C}_{5} \mathrm{H}_{10} \mathrm{O}_{5}$ & 150.55480 & 1.899 & $\uparrow$ \\
\hline 1.30 & 162.11154 & Carnitine & ESI (+) & $\mathrm{C}_{7} \mathrm{H}_{15} \mathrm{NO}_{3}$ & 161.10318 & -0.930 & $\downarrow$ \\
\hline 1.45 & 204.12184 & Acetylcarnitine & ESI (+) & $\mathrm{C}_{9} \mathrm{H}_{17} \mathrm{NO}_{4}$ & 203.11348 & -1.195 & $\uparrow$ \\
\hline 24.58 & 230.11407 & Ergothioneine & $\mathrm{ESI}(+)$ & $\mathrm{C}_{9} \mathrm{H}_{15} \mathrm{~N}_{3} \mathrm{O}_{2} \mathrm{~S}$ & 229.30031 & 0.569 & $\downarrow$ \\
\hline 41.61 & 255.23244 & Palmitic acid & ESI (-) & $\mathrm{C}_{16} \mathrm{H}_{32} \mathrm{O}_{2}$ & 256.24080 & 1.677 & + \\
\hline 1.35 & 258.10883 & Glycerophosphocholine & ESI $(+)$ & $\mathrm{C}_{8} \mathrm{H}_{20} \mathrm{NO}_{6} \mathrm{P}$ & 257.10047 & -1.270 & + \\
\hline 39.18 & 279.23239 & Linoleic acid & $\mathrm{ESI}(-)$ & $\mathrm{C}_{18} \mathrm{H}_{32} \mathrm{O}_{2}$ & 280.24075 & 0.533 & + \\
\hline 29.99 & 295.22723 & 8-hydroxy-linoleic acid & $\mathrm{ESI}(-)$ & $\mathrm{C}_{18} \mathrm{H}_{32} \mathrm{O}_{3}$ & 296.23559 & -0.458 & + \\
\hline 1.32 & 296.06451 & 5-aminoimidazole ribonucleotide & $\mathrm{ESI}(+)$ & $\mathrm{C}_{8} \mathrm{H}_{14} \mathrm{~N}_{3} \mathrm{O}_{7} \mathrm{P}$ & 295.05615 & 0.297 & + \\
\hline 59.15 & 309.27618 & Linoleic acid ethyl ester & ESI (+) & $\mathrm{C}_{20} \mathrm{H}_{36} \mathrm{O}_{2}$ & 308.26782 & -0.080 & + \\
\hline 28.48 & 312.30252 & Dimethyl guanosine & $\mathrm{ESI}(+)$ & $\mathrm{C}_{12} \mathrm{H}_{17} \mathrm{~N}_{5} \mathrm{O}_{5}$ & 311.29388 & 1.726 & $\downarrow$ \\
\hline 1.24 & 317.11334 & Mycosporin glutamicol & $\mathrm{ESI}(+)$ & $\mathrm{C}_{13} \mathrm{H}_{20} \mathrm{~N}_{2} \mathrm{O}_{7}$ & 316.10498 & 1.278 & $\uparrow$ \\
\hline 3.37 & 335.07434 & Fructose -1,6-bisphosphate & ESI (-) & $\mathrm{C}_{6} \mathrm{H}_{10} \mathrm{O}_{12} \mathrm{P}_{2}$ & 336.08392 & 1.500 & $\uparrow$ \\
\hline 28.53 & 476.27719 & Phosphatidylethanolamine (18:2/0:0) & ESI $(-)$ & $\mathrm{C}_{23} \mathrm{H}_{44} \mathrm{NO}_{7} \mathrm{P}$ & 477.28555 & -0.024 & + \\
\hline 30.57 & 478.29260 & Phosphatidylethanolamine (18:1/0:0) & $\mathrm{ESI}(-)$ & $\mathrm{C}_{23} \mathrm{H}_{46} \mathrm{NO}_{7} \mathrm{P}$ & 479.30096 & 0.095 & + \\
\hline 35.26 & 522.35986 & Phosphotidylcholine (18:1/0:0) & $\mathrm{ESI}(+)$ & $\mathrm{C}_{26} \mathrm{H}_{52} \mathrm{NO}_{7} \mathrm{P}$ & 521.3515 & 0.154 & $\downarrow$ \\
\hline 36.15 & 524.29797 & Phosphatidyserine (18:1/0:0) & $\mathrm{ESI}(+)$ & $\mathrm{C}_{24} \mathrm{H}_{46} \mathrm{NO}_{9} \mathrm{P}$ & 523.28961 & -0.082 & $\downarrow$ \\
\hline 36.80 & 595.28802 & Phosphatidylinositol (18:2/0:0) & ESI (-) & $\mathrm{C}_{27} \mathrm{H}_{49} \mathrm{O}_{12} \mathrm{P}$ & 596.29638 & 0.230 & $\downarrow$ \\
\hline 40.74 & 597.30420 & Phosphatidylinositol (18:1/0:0) & ESI (-) & $\mathrm{C}_{27} \mathrm{H}_{51} \mathrm{O}_{12} \mathrm{P}$ & 598.31256 & 0.760 & $\downarrow$ \\
\hline 16.52 & 631.38678 & Beauverolide Ka & $\mathrm{ESI}(+)$ & $\mathrm{C}_{37} \mathrm{H}_{50} \mathrm{~N}_{4} \mathrm{O}_{5}$ & 630.378411 & -0.345 & + \\
\hline
\end{tabular}

$\uparrow$ Relative concentration of the component was higher in mycelia than in spores; $\downarrow$, Relative concentration was lower in mycelia than in spores; + , Relative concentration was only found in mycelia, and not found in spores

The TCA is a key metabolic pathway that unifies carbohydrate, fat and protein metabolism. The reactions of the cycle are carried out by eight enzymes that completely oxidize acetyl-CoA into two molecules of carbon dioxide. Through catabolism of sugars, fats and proteins, a twocarbon organic product acetate in the form of acetyl-CoA is produced which enters the citric acid cycle [48]. An increase of carnitine and decrease of acetylcarnitine, succinate, oxaloacetate and fumarate suggested that the TCA was depressed and lipid metabolism was enhanced in the spores. As a result, lipid was accumulated to protect spores against harmful effects of environment or others.

\section{Conclusion}

The proposed HPLC-MS methods enable the global determination of charged species, so that they can be used as universal tools for metabolome analysis. Metabolome data, along with macroscopic and microscopic techniques were used to provide important new information of the metabolism and growth of B. bassiana spores and mycelia. Gompertz model based on macroscopic and microscopic techniques was used to detect the relation between spores elongation length and culture time. Spore elongation length was found to increase exponentially until approximately $23 \mathrm{~h}$ after cultivation, and then growth became linear. The results of PCA displayed clear differences of the components in mycelia and spores of the fungus. Metabolic pathway of $B$. bassiana spores and mycelia was established based on HPLC-MS and KEGG database, which revealed the presence of twenty-eight major components in mycelia and thirty-six compounds in spores. In the metabolic network, the decrease of 
Table 2 Metabolites putatively identified by HPLC - MS in spores extracts

\begin{tabular}{|c|c|c|c|c|c|c|c|}
\hline RT (min) & Detected mass & Metabolite & Ionization mode & $\begin{array}{l}\text { Molecular } \\
\text { formula }\end{array}$ & $\begin{array}{l}\text { Theoretical } \\
\text { mass }\end{array}$ & $\Delta$ mass (mDa) & $\begin{array}{l}\text { Relative } \\
\text { concent-rations }\end{array}$ \\
\hline 2.95 & 72.99202 & Glyoxylate & ESI (-) & $\mathrm{C}_{2} \mathrm{H}_{2} \mathrm{O}_{3}$ & 74.00039 & -1.530 & $\downarrow$ \\
\hline 64.87 & 87.00903 & Pyruvate & ESI (-) & $\mathrm{C}_{3} \mathrm{H}_{4} \mathrm{O}_{3}$ & 88.01739 & -1.360 & $\downarrow$ \\
\hline 1.30 & 90.05455 & Alanine & $\mathrm{ESI}(+)$ and $\mathrm{ESI}(-)$ & $\mathrm{C}_{3} \mathrm{H}_{7} \mathrm{NO}_{2}$ & 89.0932 & -0.405 & $\downarrow$ \\
\hline 2.95 & 99.00914 & Succinic anhydride & ESI (-) & $\mathrm{C}_{4} \mathrm{H}_{4} \mathrm{O}_{3}$ & 100.01751 & 1.470 & + \\
\hline 5.79 & 115.07640 & Fumarate & ESI $(-)$ & $\mathrm{C}_{4} \mathrm{H}_{4} \mathrm{O}_{4}$ & 116.07216 & -1.627 & $\downarrow$ \\
\hline 1.17 & 115.12245 & Dihydrouracil & ESI $(+)$ & $\mathrm{C}_{4} \mathrm{H}_{6} \mathrm{~N}_{2} \mathrm{O}_{2}$ & 114.10264 & 0.361 & + \\
\hline 2.98 & 117.07478 & Succinate & ESI (-) & $\mathrm{C}_{4} \mathrm{H}_{6} \mathrm{O}_{4}$ & 118.08804 & -0.002 & $\downarrow$ \\
\hline 1.34 & 118.08559 & Betaine & ESI $(+)$ & $\mathrm{C}_{5} \mathrm{H}_{11} \mathrm{NO}_{2}$ & 117.07704 & -0.024 & $\uparrow$ \\
\hline 45.76 & 131.06079 & Oxaloacetate & ESI (-) & $\mathrm{C}_{4} \mathrm{H}_{4} \mathrm{O}_{5}$ & 132.07156 & 1.486 & $\downarrow$ \\
\hline 3.32 & 128.03557 & Pyroglutamic acid & ESI (-) & $\mathrm{C}_{5} \mathrm{H}_{7} \mathrm{NO}_{3}$ & 129.04393 & 1.350 & + \\
\hline 1.05 & 129.13797 & Dihydrothymine & ESI $(+)$ & $\mathrm{C}_{5} \mathrm{H}_{8} \mathrm{~N}_{2} \mathrm{O}_{2}$ & 128.12922 & -0.085 & $\downarrow$ \\
\hline 2.27 & 146.04608 & Glutamic acid & ESI (-) & $\mathrm{C}_{5} \mathrm{H}_{9} \mathrm{NO}_{4}$ & 147.05444 & 1.296 & \\
\hline 64.65 & 149.04669 & Ribulose & ESI (-) & $\mathrm{C}_{5} \mathrm{H}_{10} \mathrm{O}_{5}$ & 150.05505 & 1.240 & $\downarrow$ \\
\hline 1.28 & 162.11182 & Carnitine & ESI $(+)$ & $\mathrm{C}_{7} \mathrm{H}_{15} \mathrm{NO}_{3}$ & 161.10318 & -0.930 & $\uparrow$ \\
\hline 1.23 & 173.10434 & Arginine & ESI (-) & $\mathrm{C}_{6} \mathrm{H}_{14} \mathrm{~N}_{4} \mathrm{O}_{2}$ & 174.1127 & 1.038 & + \\
\hline 1.34 & 181.07187 & Mannitol & ESI (-) & $\mathrm{C}_{6} \mathrm{H}_{14} \mathrm{O}_{6}$ & 182.08023 & 1.205 & + \\
\hline 1.43 & 204.12219 & Acetylcarnitine & ESI $(+)$ & $\mathrm{C}_{9} \mathrm{H}_{17} \mathrm{NO}_{4}$ & 203.11348 & -0.845 & $\downarrow$ \\
\hline 1.38 & 230.09485 & Ergothioneine & ESI $(+)$ & $\mathrm{C}_{9} \mathrm{H}_{15} \mathrm{~N}_{3} \mathrm{O}_{2} \mathrm{~S}$ & 229.30031 & 1.203 & $\uparrow$ \\
\hline 1.37 & 236.14839 & Ulvaline & ESI $(+)$ & $\mathrm{C}_{10} \mathrm{H}_{21} \mathrm{NO}_{5}$ & 235.14003 & -0.859 & + \\
\hline 33.64 & 299.25864 & 3-hydroxy-stearic acid & $\mathrm{ESI}(-)$ & $\mathrm{C}_{18} \mathrm{H}_{36} \mathrm{O}_{3}$ & 300.267 & 0.569 & + \\
\hline 27.63 & 302.30411 & Sphinganine & ESI $(+)$ & $\mathrm{C}_{18} \mathrm{H}_{39} \mathrm{NO}_{2}$ & 301.29575 & -1.246 & $\uparrow$ \\
\hline 2.38 & 312.12906 & Dimethyl guanosine & ESI $(+)$ & $\mathrm{C}_{12} \mathrm{H}_{17} \mathrm{~N}_{5} \mathrm{O}_{5}$ & 311.1207 & -0.025 & $\uparrow$ \\
\hline 3.32 & 315.11945 & Mycosporin glutamicol & ESI $(-)$ & $\mathrm{C}_{13} \mathrm{H}_{20} \mathrm{~N}_{2} \mathrm{O}_{7}$ & 316.12781 & 0.776 & $\downarrow$ \\
\hline 24.46 & 318.29892 & 2-amino-6-methyl-1,3,4-heptadecanetriol & ESI (+) & $\mathrm{C}_{18} \mathrm{H}_{39} \mathrm{NO}_{3}$ & 317.29056 & -1.351 & + \\
\hline 30.58 & 330.33508 & 2-amino-1,3-eicosanediol & $\mathrm{ESI}(+)$ & $\mathrm{C}_{20} \mathrm{H}_{43} \mathrm{NO}_{2}$ & 329.32672 & -1.576 & + \\
\hline 2.81 & 335.07434 & Fructose -1,6-bisphosphate & ESI (-) & $\mathrm{C}_{6} \mathrm{H}_{10} \mathrm{O}_{12} \mathrm{P}_{2}$ & 336.08392 & 3.0 & $\downarrow$ \\
\hline 27.79 & 346.32990 & 2-amino-1,3,4-eicosanetriol & $\mathrm{ESI}(+)$ & $\mathrm{C}_{20} \mathrm{H}_{43} \mathrm{NO}_{3}$ & 345.32154 & -1.671 & + \\
\hline 41.75 & 433.23291 & Phosphatidic acid (18:2/0:0) & ESI (-) & $\mathrm{C}_{21} \mathrm{H}_{39} \mathrm{O}_{7} \mathrm{P}$ & 434.24127 & 2.056 & + \\
\hline 43.20 & 435.25119 & Phosphatidic acid (18:1/0:0) & ESI (-) & $\mathrm{C}_{21} \mathrm{H}_{41} \mathrm{O}_{7} \mathrm{P}$ & 436.25955 & -2.939 & + \\
\hline 31.79 & 520.33716 & Phosphotidylcholine (18:2/0:0) & ESI $(+)$ & $\mathrm{C}_{26} \mathrm{H}_{50} \mathrm{NO}_{7} \mathrm{P}$ & 519.32880 & 1.589 & + \\
\hline 34.49 & 522.35303 & Phosphotidylcholine (18:1/0:0) & $\mathrm{ESI}(+)$ & $\mathrm{C}_{26} \mathrm{H}_{52} \mathrm{NO}_{7} \mathrm{P}$ & 521.34467 & -2.386 & $\uparrow$ \\
\hline 25.76 & 524.29108 & Phosphatidyserine (18:1/0:0) & ESI (+) & $\mathrm{C}_{24} \mathrm{H}_{46} \mathrm{NO}_{9} \mathrm{P}$ & 523.28272 & 1.724 & $\uparrow$ \\
\hline 45.33 & 538.31598 & Phosphatidyserine (19:0/0:0) & ESI (-) & $\mathrm{C}_{25} \mathrm{H}_{50} \mathrm{NO}_{9} \mathrm{P}$ & 539.32434 & 2.501 & + \\
\hline 16.13 & 566.34436 & Phosphatidyserine (21:0/0:0) & ESI (-) & $\mathrm{C}_{27} \mathrm{H}_{54} \mathrm{NO}_{9} \mathrm{P}$ & 567.35272 & 2.515 & + \\
\hline 11.48 & 595.28656 & Phosphatidylinositol (18:2/0:0) & ESI (-) & $\mathrm{C}_{27} \mathrm{H}_{49} \mathrm{O}_{12} \mathrm{P}$ & 596.29492 & -1.230 & $\uparrow$ \\
\hline 67.34 & 597.30200 & Phosphatidylinositol (18:1/0:0) & ESI (-) & $\mathrm{C}_{27} \mathrm{H}_{51} \mathrm{O}_{12} \mathrm{P}$ & 598.31036 & -1.440 & $\uparrow$ \\
\hline
\end{tabular}

$\uparrow$, Relative concentration of the component was higher in spores than in mycelia; $\downarrow$, Relative concentration was lower in spores than in mycelia; + , Relative concentration was only found in spores, and not found in mycelia.

glyoxylate, pyruvate, fumarate, alanine, succinate, oxaloacetate, dihydrothymine, ribulose, acetylcarnitine, fructose-1, 6-bisphosphate, mycosporin glutamicol, and the increase of betaine, carnitine, ergothioneine, sphingosine, dimethyl guanosine, glycerophospholipids, and in spores indicated that the change of the metabolin can keep spores in inactive conditions, protect spores against harmful effects and survive longer. The study provided the tools for understand and control the process of spores germination and outgrow to mycelia. 


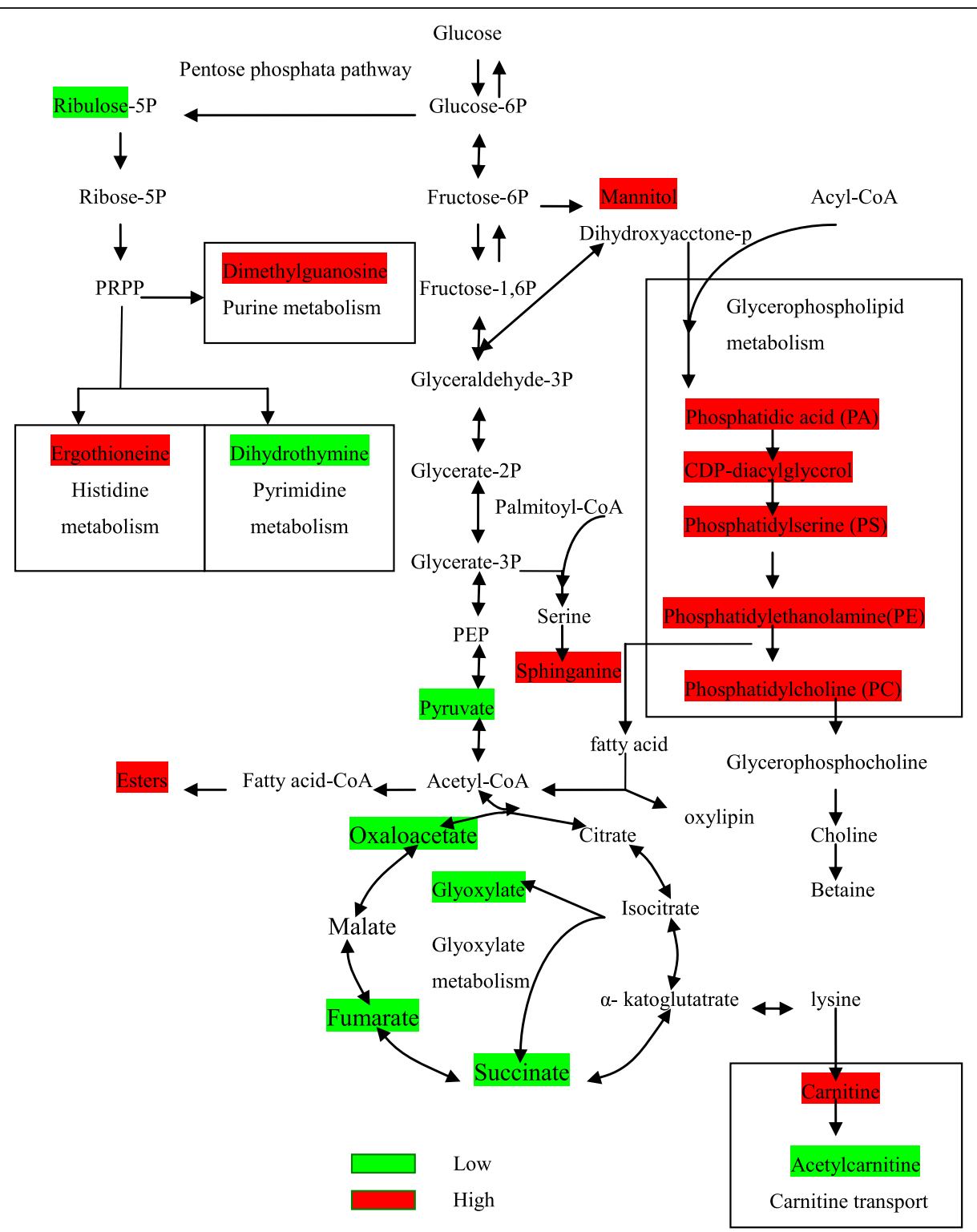

Fig. 5 General biosynthetic pathways of some metabolites in B. bassiana according to the HPLC-MS and KEGG database. Green boxes indicate metabolites whose levels lower in spores than in mycelia. White red boxes represent the levels of metabolites higher in spores than in mycelia. Abbreviations: PRPP, phosphoribosyl pyrophosphate; PEP, phosphopyruvate

\section{Methods}

\section{Microorganisms and culture medium}

B. bassiana Bb0062 provided by the Anhui Provincial Key Laboratory of Microbial Control, Anhui Agricultural University, was stored at $-20^{\circ} \mathrm{C}$ in sterilized cryovials containing $10 \%$ glycerol (in $0.02 \%$ Tween 80 solution). It was cultured on potato dextrose agar (PDA) slants (potato $200 \mathrm{~g} / \mathrm{L}$, glucose $20 \mathrm{~g} / \mathrm{L}$ and agar $20 \mathrm{~g} / \mathrm{L}$ ) at $26{ }^{\circ} \mathrm{C}$ for 7 days, and then stored at $4{ }^{\circ} \mathrm{C}$ until use.

\section{Preparation of inocula}

$B$. bassiana was cultured on PDA medium mentioned above at $26{ }^{\circ} \mathrm{C}$ for 7 days to obtain heavily sporulating cultures. Spores were then suspended in sterile distilled water containing $0.02 \%(\mathrm{v} / \mathrm{v})$ Tween 80 by gently scraping the agar surface with a sterile spatula, and then filtered through two layers of gauze to remove any debris (mostly mycelial fragments). The final spore concentration was adjusted to $1 \times 10^{6}$ spores $/ \mathrm{mL}$ and used as quickly as possible.

\section{Assessment of germination and outgrowth}

Portions $(100 \mu \mathrm{L})$ of the inoculum (B. bassiana), containing approximately $10^{5}$ spores, were surface plated aseptically on PDA. After inoculation, plates were sealed with parafilm to prevent moisture loss, and stored at 
$26{ }^{\circ} \mathrm{C}$ for 2 days. To monitor the kinetic behavior of the $B$. bassiana spores for prolonged periods (from germination to mycelium formation), computer morphometry (Leica Microscopy System Ltd, DMI 4000B, Germany) was employed to examine spore germination and mycelia outgrowth. Germination time was defined as the time at which the length of the germ tube was equal to the diameter of the swollen spore. Samples were measured every $2 \mathrm{~h}$ until $32 \mathrm{~h}$. Images was analysed by Image-Pro Plus image analysis software version 6.3 (MediaCybernetics Inc., Bethesda, United States) and an auto-focus system.

For the germination study, length of germ tube over time was fitted to the modified Gompertz equation (Eq. (1)) [49] for the estimation of the germination kinetic parameters (ke and c):

$$
L=L_{\max } \exp \left(-\exp \left[\frac{k e}{L_{\max }}(c-t)+1\right]\right)
$$

where $\mathrm{t}(\mathrm{h})$ is the time, $\mathrm{L}$ indicates length of spores elongation at time $t, L_{\max }$ represents length of hypha $t \rightarrow+\infty$, ke signifies the slope of tangent line through the inflection point, $\mathrm{c}$ is the time when hyphal extention reach to maximum speed.

\section{Mycelia and spores preparation for HPLC-MS analysis}

Mycelia were harvested after $32 \mathrm{~h}$ of growth by a scoop, suspended in sterile water, and then filtered through two layers of gauze to remove debris, subsequently frozen in liquid nitrogen to terminate metabolism, and kept at $-80{ }^{\circ} \mathrm{C}$. Spores were collected at 7 days post-inoculation by scrapping the colony into $0.01 \%$ Tween 80 solution, and the contents were vortexed and filtered through a $10 \mu \mathrm{m}$ microfiltration membrane to remove any debris. The filtrate was transferred to a $50 \mathrm{~mL}$ centrifuge tube and centrifuged for $10 \mathrm{~min}$ at $8000 \mathrm{rpm}$. The precipitate was resuspended in $2 \mathrm{~mL}$ of distilled water and transferred to a $5 \mathrm{~mL}$ centrifuge tube, centrifuged for $10 \mathrm{~min}$ at $10,000 \mathrm{rpm}$, and then frozen in liquid nitrogen to terminate metabolism. Finally, the spores were kept at $-80{ }^{\circ} \mathrm{C}$. Three independent biological replicates were measured per assay.

Mycelia and spores were lyophilized until a constant weight was attained. Mycelia were then crushed into a fine powder and then kept at $4{ }^{\circ} \mathrm{C}$ until extraction. Ten milligrams of sample was extracted with $2 \mathrm{~mL}$ of $80 \%$ methyl alcohol (Tedia company, USA, HPLC grade), followed by $1 \mathrm{~min}$ of vortexing and subsequent sonication (12-KHz, 8-s exposure followed by a 4-s rest interval) for $1 \mathrm{~h}$. Samples were further kept at $4{ }^{\circ} \mathrm{C}$ for $12 \mathrm{~h}$ in the dark. After centrifugation at $8000 \mathrm{rpm}$ for $10 \mathrm{~min}, 1.8 \mathrm{~mL}$ of supernatant was collected and dried with a centrifugal concentrator. All samples were stored at $-80{ }^{\circ} \mathrm{C}$ until analysis. The dried extracts were redissolved ultrasonically in $300 \mu \mathrm{L}$ of $80 \%$ methanol and filtered through a $0.22 \mu \mathrm{m}$ polyvinylidene fluoride membrane filter before HPLC MS analysis.

\section{HPLC - MS conditions}

In order to determine retention time and to obtain extract HPLC profiles, HPLC was performed on a Thermo-Fisher UPLC system (Thermo-Fisher, SanJose, CA, USA) coupled with an LTQ XL mass spectrometer. HPLC analyses were conducted on a C18 reversed-phase (RP)

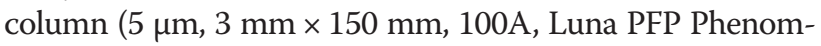
enex, Torrance, CA, USA). The parameters were as follows: injection volume, $5 \mu \mathrm{L}$; column temperature, $40{ }^{\circ} \mathrm{C}$; flow rate, $0.3 \mathrm{~mL} / \mathrm{min}$; and the eluates were monitored by fulllength scan from 200 to $600 \mathrm{~nm}$. The mobile phase was (A) $0.1 \%$ formic acid (Anaqua Chemical Supply, USA, HPLC grade) in water and (B) $0.1 \%$ formic acid in acetonitrile (Merck, Germany, HPLC grade), and gradient elution was carried out: $5 \%$ B for 0-3 min, 5-100 \% B for 3-50 min, and $100 \% \mathrm{~B}$ for $50-60 \mathrm{~min}$. The mass spectrometer parameter settings used for the measurement were as follows: ionization mode, for both positive and negative; gas temperature, $350{ }^{\circ} \mathrm{C}$; drying gas, $12 \mathrm{~L} / \mathrm{min}$; nebulizer pressure, 45 psi; capillary voltage, $4000 \mathrm{~V}$ in positive mode and $3500 \mathrm{~V}$ in negative mode; fragmentor voltage, $215 \mathrm{~V}$ in positive mode and $170 \mathrm{~V}$ in negative mode; skimmer voltage, $60 \mathrm{~V}$; and OCT 1 RF, $250 \mathrm{~V}$. Data acquisition was performed in the $\mathrm{m} / \mathrm{z}$ range of $50-1100 \mathrm{Da}$.

\section{Data processing and statistical analysis}

All data were processed using the Xcalibur software provided by the manufacturer. After all of the detected peaks were subjected to noise-reduction in both the HPLC and MS domains, the analytical peaks were processed by the software. A list of peak intensities with retention times and $\mathrm{m} / \mathrm{z}$ data pairs was generated. The intensity of each peak was normalized by the sum of all of the peak intensities. Peaks with signal-to-noise $(\mathrm{S} / \mathrm{N})$ ratios lower than 5 were rejected. PCA were performed by SPSS v18.0 (IBM SPSS Statistics, Ontario, Canada) to envisage the different components of $B$. bassiana spores and mycelia.

\section{Metabolite identification}

The small-molecule inventory (SMI) or metabolome is a pattern of molecules that reflects the cell's status. The molecular formula calculated by the Xcalibur software was predicted, and based on a general understanding of fungi metabolism pathways by searching web databases (Dictionary of Natural Products, METLIN, PUBCHEM, and CHEMSPIDER). The exact monoisotopic masses of possible metabolites were calculated based on their elemental compositions. Putative biomarkers were verified by its elution order (polarity) and structure characteristics. The ambiguous metabolites were identified by 
comparison to authentic compounds available or referring to the published literature about fungi, especially entomopathogenic fungi.

\section{Abbreviations}

ESI: Electrospray ionization; HPLC-MS: High performance liquid chromatography-mass spectrometry; HX: Hexokinase; KEGG: Kyoto Encyclopedia of Genes and Genomes; MDH: Mannitol 2-dehydrogenase; MPDH: Mannitol 1-phosphate dehydrogenase; MPP: Mannitol 1-phosphate phosphatase; PCA: Principal component analysis; PEP: phosphopyruvate; PRPP: Phosphoribosyl pyrophosphate; SMI: Small-molecule inventory; TCA: Tricarboxylic acid.

\section{Competing interests}

The authors declare that they have no competing interests.

\section{Authors' contributions}

Conceived and designed the experiments: HXL. Performed the experiments: $H X L, M X G$. Measured, photographed and analyzed the experiments: HXL, HL. Analyzed the data: HXL. Contributed reagents/materials/analysis tools: HXL, $X S Z$, JYQ. Contributed to the writing of the manuscript: HXL, ZMZ. All authors have read and approved the final manuscript.

\section{Acknowledgments}

This research was funded by Anhui Provincial Natural Science Foundation (1308085MA07) and key 863 Fund of China (2014AA021704).

\section{Author details}

'Jujube Scientific Research and Applied Center, Life Science College, Luoyang Normal University, 471000 Luoyang, P. R. China. ${ }^{2}$ Key Laboratory of Ion Beam Bioengineering, Hefei Institutes of Physical Science, Chinese Academy of Sciences and Anhui Province, Hefei, Anhui 230031, P. R. China.

\section{Received: 20 January 2015 Accepted: 28 October 2015}

\section{Published online: 19 November 2015}

\section{References}

1. Leathers TD, Gupta CS, Alexander NJ. Mycopesticides: status, challenges and potential. J Ind Microbiol Biot. 1993;12:69-75.

2. Pu SC, Chen MJ, Ma ZY, Xie L, Li ZZ, Bo H. Genotyping isolates of the entomopathogenic fungus Beauveria bassiana sensu lato by multi-locus polymerase chain reaction-denaturing gradient gel electrophoresis (PCR-DGGE) analysis. Afr J Biotechnol. 2010;9:4290-4.

3. Xiao GH, Ying SH, Zheng P, Wang ZL, Zhang SW, Xie XQ et al. Genomic perspectives on the evolution of fungal entomopathogenicity in Beauveria bassiana. Sci Rep. 2012;2:483-92.

4. Tarocco F, Lecuona RE, Couto AS, Arcas JA. Optimization of erythritol and glycerol accumulation in conidia of Beauveria bassiana by solid-state fermentation, using response surface methodology. Appl Microbiol Biotechnol. 2005;68:481-8.

5. Taylor B, Edgington S, Luke B, Moore D. Yield and germination of the entomopathogenic fungus Beauveria bassiana when grown on different rice preparations. J Stored Prod Res. 2013;53:23-6.

6. Gouli V, Gouli S, Kim JS. Production of Beauveria bassiana Air conidia by means of optimization of biphasic system technology. Braz Arch Biol Technol. 2014;57:571-7.

7. Fang WJ, Leng $B$, Xiao YH, Jin K, Ma JC, Fan YH, et al. Cloning of Beauveria bassiana chitinase gene Bbchit1 and its application to improve fungal strain virulence. Appl Environ Microbiol. 2005;71:363-70.

8. Zimmermann G. Review on safety of the entomopathogenic fungi Beauveria bassiana and Beauveria brongniartii. Biocontrol Sci Tech. 2007;17:553-96.

9. Gougouli M, Koutsoumanis KP. Modeling germination of fungal spores at constant and fluctuating temperature conditions. Int J Food Microbiol. 2012;152:153-61.

10. Bainbridge BW. Macromolecular composition and nuclear division during spore germination in aspergillus nidulans. J Gene Microbiol. 1971;66:319-25.

11. Fillinger S, Chaveroche MK, Dijck PV, Vries RD, Ruijter G, Thevelein J, et al. Trehalose is required for the acquisition of tolerance to a variety of stresses in the filamentous fungus Aspergillus nidulans. Microbiology. 2001;147:1851-62
12. Bradshaw RE, Bird DM, Brown $\mathrm{S}$, Gardiner RE, Hirst P. Cytochrome $\mathrm{C}$ is not essential for viability of the fungus Aspergillus nidulans. Mol Genet Genomics. 2001;266:48-55.

13. Taubitz A, Bauer B, Heesemann J, Ebel F. Role of respiration in the germination process of the pathogenic mold aspergillus fumigatus. Curr Microbiol. 2007:54:354-60.

14. Osherov N, May G. Conidial germination in aspergillus nidulans requires RAS signaling and protein synthesis. Genetics Soc America. 2000;155:647-56.

15. Papagianni M. Fungal morphology and metabolite production in submerged mycelial processes. Biotechnol Adv. 2004;22:189-259.

16. Feofilova EP, Ivashechkinb AA, Alekhinc Al, Sergeeva YE. Fungal Spores: Dormancy, Germination, Chemical Composition, and Role in Biotechnology (Review). Appl Biochem Micro. 2012;48:1-11.

17. Tomoyoshi S, Yoshiaki O, Yuki U, Hisako N, Masaru T, Takaaki N. Quantitative metabolome analysis using capillary electrophoresis mass spectrometry. J Proteome Res. 2003;2:488-94.

18. Wagner S, Scholz K, Donegan M, Burton L, Wingate J, Volkel W. Metabonomics and biomarker discovery: LC-MS metabolic profiling and constant neutral loss scanning combined with multivariate data analysis for mercapturic acid analysis. Anal Chem. 2006;78:1296-305.

19. Lee JH, Kim NS, Han KM, Kim SH, Cho S, Kim WS. Monitoring by LC-MS/MS of 48 compounds of sildenafil, tadalafil, vardenafil and their analogues in illicit health food products in the Korean market advertised as enhancing male sexual performance. Food Addit Contam A. 2013;30:1849-57.

20. Shi XW, Zhang K, Xue N, Su LF, Ma GX, Qi JL, et al. Differentiation of genuine Inula britannica $L$. and substitute specimens based on the determination of 15 components using LC-MS/MS and principal components analysis. Food Chem. 2013;141:4019-25.

21. Napolitano A, Akay S, Mari A, Bedir E, Pizza C, Piacente S. An analytical approach based on ESI-MS, LC-MS and PCA for the quali-quantitative analysis of cycloartane derivatives in Astragalus spp. J Pharmaceut Biomed. 2013:85:46-54

22. Raamsdonk LM, Teusink B, Broadhurst D, Zhang N, Hayes A, Walsh MC, et al. A functional genomics strategy that uses metabolome data to reveal the phenotype of silent mutations. Nat Biotechnol. 2001;19:45-50.

23. Ideker T, Thorsson V, Ranish JA, Christmas R, Buhler J, Eng JK, et al. Integrated genomic and proteomic analyses of a systematically perturbed metabolic network. Science. 2001;292:929-34.

24. Garcia D, Ramos AJ, Sanchis V, Marín S. Predicting mycotoxins in foods: a review. Food Microbiol. 2009:26:757-69.

25. Trinci APJ. A kinetic study of the growth of aspergillus nidulans and other fungi. J Gen Microbiol. 1969:57:11-24.

26. Trinci APJ. Influence of the width of the peripheral growth zone on the radial growth rate of fungal colonies on solid media. J Gen Microbiol. 1971;67:325-44.

27. Camacho J, Picó J, Ferrer A. Data understanding with PCA: structural and variance information plots. Chemometr Intell Lab. 2010;100:48-56.

28. Pan ZZ, Gu HW, Talaty N, Chen HW, Shanaiah N, Hainline BE, et al. Principal component analysis of urine metabolites detected by NMR and DESI-MS in patients with inborn errors of metabolism. Anal Bioanal Chem. 2007;387:539-49.

29. Herrgård MJ, Swainston N, Dobson P, Dunn WB, Arga KY, Arvas M, et al. A consensus yeast metabolic network reconstruction obtained from a community approach to systems biology. Nat Biotechnol. 2008;26:1155-60.

30. Kruger NJ, Schaewen AV. The oxidative pentose phosphate pathway: structure and organisation. Curr Opin Plant Biol. 2003;6:236-46.

31. Keller MA, Turchyn AV, Ralser M. Non-enzymatic glycolysis and pentose phosphate pathway-like reactions in a plausible Archean ocean. Mol Syst Biol. 2014:10:725-5.

32. Emes MJ, Neuhaus HE. Metabolism and transport in non-photosynthetic plastids. J Exp Bot. 1997:48:1995-2005.

33. Juhnke $H$, Krems B, Kötter $P$, Entian KD. Mutants that show increased sensitivity to hydrogen peroxide reveal an important role for the pentose phosphate pathway in protection of yeast against oxidative stress. Mol Gen Genet. 1996;252:456-64.

34. Hand CE, Honek JF. Biological chemistry of naturally occurring thiols of microbial and marine origin. J Nat Prod. 2005;68:293-308.

35. Misiti F, Castagnola M, Zuppi C, Giardina B, Messana I. Role of ergothioneine on S-nitrosoglutathione catabolism. Biochem J. 2001;356:799-804.

36. Cheah IK, Halliwell B. Ergothioneine; antioxidant potential, physiological function and role in disease. Biochim Biophys Acta. 1822;2012:784-93. 
37. Bello MH, Barrera-Perez V, Morin D, Epstein L. The Neurospora crassa mutant Nc $\Delta$ Egt-1 identifies an ergothioneine biosynthetic gene and demonstrates that ergothioneine enhances conidial survival and protects against peroxide toxicity during conidial germination. Fungal Genet Biol. 2012;49:160-72.

38. Bacon CW, Sussman AS, Paul AG. Identification of a self-inhibitor from spores of Dictyostelium discoideum. J Bacteriol. 1973;133:1061-3.

39. Pluskal T, Hayashi T, Saitoh S, Fujisawa A, Yanagida M. Specific biomarkers for stochastic division patterns and starvation-induced quiescence under limited glucose levels in fission yeast. FEBS J. 2011;278:1299-315.

40. Nyhan WL. Disorders of purine and pyrimidine metabolism. Mol Genet Metab. 2005;86:25-33.

41. Furberg $\mathrm{S}$, Jensen $\mathrm{LH}$. The crystal and molecular structure of dihydrothymine. J Am Chem Soc. 1967;90:470-4.

42. Hult K, Gatenbeck S. Production of NADPH in the mannitol cycle and its relation to polyketide formation in Alternaria alternata. Eur J Biochem. 1978:88:607-12.

43. Voegele RT, Hahn M, Lohaus G, Link T, Heiser I, Mendgen K. Possible roles for mannitol and mannitol dehydrogenase in the biotrophic plant pathogen uromyces fabae. Plant Physiol. 2005;137:190-8.

44. Tsitsigiannis DI, Keller NP. Oxylipins as developmental and host-fungal communication signals. Trends Microbiol. 2007;15:109-18.

45. Jegorov A, Paizs B, Kuzma M, Zabka M, Landa Z, Sulc M, et al. Extraribosomal cyclic tetradepsipeptides beauverolides: profiling and modeling the fragmentation pathways. J Mass Spectrom. 2004;39:949-60.

46. Takabe K, Paugh SW, Milstien S, Spiegel S. "Inside-Out" signaling of sphingosine-1-phosphate: therapeutic targets. Pharmacol Rev. 2008;60:181-95.

47. Spiegel S, Merrill AH. Sphingolipid metabolism and cell growth regulation. Faseb J. 1996:10:1388-97.

48. Vagelos PR, Alberts AW, Martin DB. Studies on the mechanism of activation of acetyl coenzyme a carboxylase by citrate. J Biol Chem. 1963;238:533-40.

49. Zwietering $\mathrm{MH}$, Jongenburger I, Rombouts FM, Riet KVT. Modeling of the bacterial growth curve. Appl Environ Microbiol. 1990;56:1875-81.

\section{Submit your next manuscript to BioMed Central and take full advantage of:}

- Convenient online submission

- Thorough peer review

- No space constraints or color figure charges

- Immediate publication on acceptance

- Inclusion in PubMed, CAS, Scopus and Google Scholar

- Research which is freely available for redistribution 